\title{
Thermo-Mechanical Parametric Studies of Fixed Mask 1 and Photon Shutter 2 for APS Front Ends
}

\author{
H. L. T. Nian, T. M. Kuzay, and I. C. A. Sheng
}

\author{
DISCLAIMER
}

This report was prepared as an account of work sponsored by an agency of the United States Government. Neither the United States Government nor any agency thereof, nor any of their employees, makes any warranty, express or implied, or assumes any legal liability or responsibility for the accuracy, completeness, or usefulness of any information, apparatus, product, or process disclosed, or represents that its use would not infringe privately owned rights. Reference herein to any specific commercial product, process, or service by trade name, trademark, manufacturer, or otherwise does not necessarily constitute or imply its endorsement, recommendation, or favoring by the United States Government or any agency thereof. The views and opinions of authors expressed herein do not necessarily state or reflect those of the United States Government or any agency thereof.

September 3, 1992

\section{Experimental Facilities Division \\ Advanced Photon Source Argonne National Laboratory}




\section{DISCLAIMER}

Portions of this document may be illegible in electronic image products. Images are produced from the best available original document. 


\title{
Thermo-Mechanical Parametric Studies of Fixed Mask 1 and Photon Shutter 2 for APS Front Ends
}

\author{
H. L. Thomas Nian, Tuncer M. Kuzay, and I. C. Albert Sheng \\ Argonne National Laboratory \\ 9700 S. Cass Ave., Argonne, IL 60439
}

\begin{abstract}
Fixed Mask 1 (FM1) and Photon Shutter 2 (PS2) are two of the critical elements on the front end of the beamlines at the Advanced Photon Source (APS) now under construction at Argonne National Laboratory (ANL). FM1 and PS2 use an enhanced heat transfer tube developed at ANL. Due to a high localized thermal gradient on these components, inclined geometry is used in their design to spread the footprint of the $\mathrm{x}$-ray beam. Complete closed form solutions for steady state conditions have been developed for the analyses of the thermal and thermo-mechanical behavior of FM1 and PS2. A modified Manson-Coffin fatigue relation is proposed to predict the predict the thermal fatigue. The maximum temperatures and maximum effective stresses have been parametrically studied. Fatigue-failure life predictions are presented for the FM1 and PS2 designs.
\end{abstract}

\section{Introduction}

Fixed Mask 1 (FM1) and Photon Shutter 2 (PS2) are two of the critical elements on the front end [1] of the beamlines at the Advanced Photon Source (APS) now under construction at Argonne National Laboratory (ANL). FM1 and PS2 use an enhanced heat transfer tube developed at ANL [2]. Due to large thermal loads on these components, inclined geometry is used in their design to spread the footprint of the $\mathrm{x}$-ray beam. To address the thermal and thermo-mechanical issues, analytical studies [3] have been applied to a simplified model [2] of these components. The front-end design includes a pair of fixed masks (FM) and another pair of photon shutters (PS). The FMs contain the X-ray beam, whereas the PSs fully intercept it. However, both components are designed to withstand the $x$-ray beam coming off the most powerful APS ID, currently, a 2.5-m-long undulator designated Undulator A. The 2.5-m-long Undulator A has a total power of $5.2 \mathrm{~kW}$. Future plans for the APS include a 5 -m-long Undulator A with a total power of $10.4 \mathrm{~kW}$. This paper deals with $\mathrm{x}$-rays from the $2.5-\mathrm{m}$ ID. However, the analysis will be extended to the future $5-\mathrm{m}$ device.

Research, development, and analysis on FMs and PSs have much in common. The FM and the PS share a similar flow tube that offers a highly enhanced heat transfer feature [2]. The FM is a box-like aperture with tapered vertical and horizontal sides. The sides are composed of the enhanced heat transfer tube set at small grazing angles to the beam. The PS, on the other hand, is built like a "hockey stick" coil [4] set horizontally at a small grazing angle of 1.5 to 2 degrees to the beam. Therefore, the horizontal tubes of both the FM and the PS share the same analysis. The vertical tubes of FM1 have less line density $\left(\frac{W}{c m}\right)$ heat flux than the horizontal tubes, thus, the resulting temperatures and stresses are smaller. 
The high energy photon beam striking these components will result in large localized temperature gradients which causes inelastic deformation. In order to predict the thermo-mechanical behavior of these components during cyclic heating, a complete closed form solution for steady state conditions has been developed, and the ANSYS finite element code has been applied to verify the results. A modified Manson-Coffin fatigue relation is proposed to predict the thermal fatigue.

The x-ray beam has a complex profile, Gaussian in the vertical direction and parabolic in the horizontal direction as shown in Fig. 1 [5]. An analysis using the closed form solution has been carried out with a Gaussian beam profile spread in the horizontal plane at a grazing angle. An analysis using ANSYS-applied real-beam-profile strikes on these components was carried out to verify the analytical solution.

Both Glidcop AL-15 [6] and oxygen-free copper (OFC) are used to fabricate these components. Glidcop has much better fatigue strength above $150^{\circ} \mathrm{C}$ than does OFC [7]. The thermal fatigue properties of metal depend on the amplitude and frequency of thermal loading. The purpose of using a Glidcop plate is to let the beam strike the Glidcop surface, while the OFC acts as a cooling sub-structure. (The Glidcop plate is bonded to the OFC sub-structure.)

\section{Nomenclature}

\begin{tabular}{|c|c|}
\hline $\mathrm{T}:$ & Temperature $\quad\left({ }^{\circ} \mathrm{C}\right)$ \\
\hline$\sigma_{i j}:$ & Stress Component \\
\hline k: & Thermal Conductivity $\quad\left(\mathrm{W} / \mathrm{m} \cdot{ }^{\circ} \mathrm{C}\right)$ \\
\hline XYZ: & Fixed Coordinate \\
\hline q: & Heat Flux $\quad\left(W / m^{2}\right)$ \\
\hline $\mathrm{t}:$ & Thickness of Plate (m) \\
\hline h: & Convective Heat Transfer Coefficient $\quad\left(\mathrm{W} / \mathrm{m}^{2} \cdot{ }^{\circ} \mathrm{C}\right)$ \\
\hline $\mathrm{T}_{\infty}:$ & Ambient Temperature $\quad$ (assumed to be $32.2^{\circ} \mathrm{C}$ ) \\
\hline 1: & Length of the Plate $(\mathrm{m})$ \\
\hline b: & Width of the Plate ( $\mathrm{m})$ \\
\hline a: & Width where q Applied to Absorber \\
\hline$r_{\circ}$ & Standard Deviation ( $\mathrm{m}$ ) \\
\hline$\nu:$ & Poisson's Ratio \\
\hline$\alpha_{t}:$ & Thermal Expansion Coefficient \\
\hline
\end{tabular}

\section{Analytical Solution}

The closed form analytical solution was developed for a simplified model using Gaussiandistributed heat flux. The channel tube is stretched into a plate as shown in Fig. 2, keeping the water-cooled area constant [2]. The thermo-analytical model can be applied to any thermal beam. In the following section, the energy equation, boundary conditions, and solution are described. The model does provide a good approximation for the channel tube. 
Consequently, the thermal stress and the deformation can also be expressed and approximated in closed form. From these equations, we can follow parametrically the trend of the thermal gradient and the thermal stress due to the temperature field created by the beam.

\subsection{Temperature Field}

A two-dimensional, steady-state boundary value problem was assumed in our analysis [3]. Because properties of Glidcop and OFC are similar, we assumed they are a single material. Hence, the heat equation is

$$
\frac{\partial^{2} T}{\partial x^{2}}+\frac{\partial^{2} T}{\partial y^{2}}=0
$$

The boundary conditions are

$$
\begin{array}{ll}
-k \frac{\partial T}{\partial y}(x, 0)=q_{o} \exp \left(-\frac{x^{2}}{r_{o}^{2}}\right) & 0 \leq x \leq a . \\
-k \frac{\partial T}{\partial y}(x, 0)=0 & a<x \leq b \\
-k \frac{\partial T}{\partial y}(x, t)=h_{c}\left(T-T_{\infty}\right) & \\
\frac{\partial T}{\partial x}(0, y)=\frac{\partial T}{\partial x}(b, y)=0 . &
\end{array}
$$

The solutions give

$$
\theta=C_{o}\left[\eta-1-\frac{1}{B i}\right]+\sum_{m=1}^{\infty} C_{m} e^{-\lambda_{m} \eta} \cos \left(\lambda_{m} \xi\right)\left[1+\frac{\lambda_{m}-B i}{\lambda_{m}+B i} e^{2 \lambda_{m}(\eta-1)}\right]
$$

where

$$
\begin{array}{cc}
\alpha=\frac{a}{t}, \quad \beta=\frac{b}{t}, \quad \xi=\frac{x}{t} \\
\eta=\frac{y}{t}, \quad \theta=\frac{k\left(T-T_{\infty}\right)}{q t}, \quad B i=\frac{h_{c} t}{k}, \\
C_{o}=-\frac{r \sqrt{\pi}}{2 \alpha} \operatorname{erf}\left(\frac{\alpha}{r}\right),
\end{array}
$$

er $f(. .$.$) is known to be the error function defined by [8], and$

$$
C_{m}=-\frac{\sqrt{\pi} r \exp \left(-\frac{r^{2} \lambda_{m}^{2}}{4}\right) \operatorname{Re}\left[\operatorname{erf}\left(\frac{2 \alpha+i r^{2} \lambda_{m}}{2 r}\right)\right]}{\lambda_{m} \alpha\left(-1+e^{-2 \lambda_{m}} \frac{\lambda_{m}-B i}{\lambda_{m}+B i}\right)}, \quad \lambda_{m}=\frac{m \pi}{\beta}, \quad m \in N .
$$


$\operatorname{Re}(z)$ is the real part of the complex variable $z ; i$ is the imaginary number defined by $\sqrt{-1}=i$.

The x-ray beam has a complex profile, Gaussian in the vertical direction and parabolic in the horizontal direction. In order to use the closed form solution described above, we have to fit the beam power (shown in Fig. 1), which strikes FM1 and PS2, to a Gaussian-distributed heat flux. By using the least squares method, we found the standard deviation for the power at different distances and angles.

\section{2 $\quad$ Stress Field}

The magnitude of the cross section ( $x y$ plane) of these devices is much smaller than that of the length ( $z$ axis). Therefore they behave as thermo-elastic beams that are subject only to thermal loading. The practical analysis of elastic beams under thermal loading is usually performed under Bernoulli-Euler rules [9]. That is, sections that are plane and perpendicular to the axis before loading remain so after loading, and the effect of lateral contraction may be neglected. The only nonzero stress component is $\sigma_{z z}$, which satisfies [9]:

$$
\left(\frac{\partial^{2}}{\partial \xi^{2}}+\frac{\partial^{2}}{\partial \eta^{2}}\right)\left(\bar{\sigma}_{z z}+\gamma \theta\right) \stackrel{\cdot}{=} 0
$$

where

$$
\bar{\sigma}_{z z}=\frac{\sigma_{z z}}{E}, \quad \gamma=\frac{\alpha_{t} q t}{k} .
$$

For any cross section, the total force and moments have to be in equilibrium. That is,

$$
\int \sigma_{z z} d A=\int \sigma_{z z} \xi d A=\int \sigma_{z z} \eta d A=0
$$

where $\int \ldots d A$ denotes the area integral over the cross section. From Eq. (7), the general solution is

$$
\bar{\sigma}_{z z}=-\gamma \theta+k_{0}+k_{1} \xi+k_{2} \eta
$$

where

$$
\begin{aligned}
k_{1}= & -\frac{24 \gamma r \sqrt{\pi}}{\alpha^{4}} \sum_{m=1,3,5, . .}^{\infty} \frac{\exp \left(-\frac{r^{2} \lambda_{m}^{2}}{4}\right) \operatorname{Re}\left[\operatorname{erf}\left(\frac{2 \alpha+i r^{2} \lambda_{m}}{2 r}\right)\right]}{\lambda_{m}^{4}} . \\
& \cdot\left(1-\frac{2 B i e^{-\lambda_{m}}}{\left(\lambda_{m}+B i\right)-e^{-2 \lambda_{m}}\left(\lambda_{m}-B i\right)}\right) \\
k_{0}= & \frac{\gamma r \sqrt{\pi}}{2 \alpha} \operatorname{erf}\left(\frac{\alpha}{r}\right)+\frac{\gamma r \sqrt{\pi}}{2 \alpha B i} \operatorname{erf}\left(\frac{\alpha}{r}\right)-\frac{k_{1} \alpha}{2} \\
k_{2}= & -\frac{(12+5 B i) \gamma r \sqrt{\pi}}{2 \alpha B i} \operatorname{erf}\left(\frac{\alpha}{r}\right) .
\end{aligned}
$$


For more details about the analysis please refer to [3].

The effective stress from the closed form solution was calculated based on the assumption that the tube was stretched into a flat plate. Calculation of the temperature and stress at the bonding surface was based on both materials being a single material. Normally, stress discontinuity will occur at the bonding surface due to differences in material properties, such as the thermal expansion coefficients and Young's moduli. It is tedious to derive solutions to reconcile discontinuity in stress at the bonding surface. Note that, in the closed form solution for two-layer materials, the interface is expected to have higher stress than is found in the closed form solution presented here.

\section{Numerical Solution}

A three-dimensional finite element analysis was carried out.to verify the closed form solution for these components. The convective heat transfer coefficient has a minimum value of 3 $\frac{W}{\mathrm{~cm}^{2}} \cdot{ }^{\circ} \mathrm{C}[2]$. The radiation effect is negligible in our temperature range (about $200^{\circ} \mathrm{C}$ ).

\section{Results and Discussion}

The parameters that are commonly used in both FM1 and PS2 are as follows:

The Power from 2.5-m Undulator A Conductivity of Glidcop Conductivity of OFC Young's Modulus of Glidcop Young's Modulus of OFC Thermal Exp. Coef. of Glidcop Thermal Exp. Coef. of OFC Poisson Ratio (Closed Form) Poisson Ratio of Glidcop Poisson Ratio of OFC
Q $5000 \mathrm{~W}$

$K \quad 365 \mathrm{~W} /\left(\mathrm{m}^{\circ} \mathrm{C}\right)$

$K \quad 391 \mathrm{~W} /\left(\mathrm{m}^{\circ} \mathrm{C}\right)$

E $1.3 \times 10^{5} \mathrm{MPa}$

E $1.15 \times 10^{5} \mathrm{MPa}$

$\alpha \quad 16.6 \times 10^{-6} \frac{1}{{ }^{\circ} C}$

$\alpha \quad 17.7 \times 10^{-6} \frac{1}{{ }^{\circ} \mathrm{C}}$

$\nu \quad 0$

$\nu \quad .33$

$\nu \quad .343$

\subsection{FM1}

The parameters that are used in the FM1 analysis are as follows:

$\begin{array}{lll}\text { Incident Beam Angle } & \theta & 2^{\circ} \\ \text { Distance from the Source } & l & 20.3 \text { meter } \\ \text { Peak Power } & q_{0} & 14 \frac{W}{m^{2}}\end{array}$


Figures 3 and 4 show the maximum temperature on the heating surface and cooling channel wall respectively, of the Glidcop material. From Fig. 3, we note that the maximum temperature has an optimal value. For example, for $\mathrm{h}=3 \mathrm{~W} /\left(\mathrm{cm}^{2}{ }^{\circ} \mathrm{C}\right)$, the optimal thickness is $5 \mathrm{~mm}$ to obtain a minimum surface temperature of about $215^{\circ} \mathrm{C}$. Lower temperatures can only be obtained with higher " $h$ " values, above $h=3 \mathrm{~W} /\left(\mathrm{cm}^{2}{ }^{\circ} \mathrm{C}\right)$. From Fig. 4 , it is seen that, under these conditions, the maximum cooling channel temperature will be about $125^{\circ} \mathrm{C}$. Increasing the channel wall thickness (Glidcop plus OFC) from $5 \mathrm{~mm}$ to $10 \mathrm{~mm}$ will help reduce the cooling channel wall temperature to $90^{\circ} \mathrm{C}$, while keeping the maximum temperature about the same $\left(220^{\circ} \mathrm{C}\right)$.

Figure 5 shows the maximum effective stress on the Glidcop surface. The slopes of the maximum effective stress curves match the maximum temperature curves as expected.

Figures 6 and 7 show the maximum temperature and maximum effective stress, respectively, at the bonding surface for a 3.175-mm-thick OFC tube. Figure 7 shows the trend of the stress at the bonding surface if both materials have exactly the same properties. It is desirable to keep the temperature and thermal stress low at the interface to attain a safety factor of 4 or better so that one does not need to consider the thermal fatigue in OFC. For example, for $\mathrm{h}=3 \mathrm{~W} /\left(\mathrm{cm}^{2}{ }^{\circ} \mathrm{C}\right)$ with a $3 \mathrm{~mm}$ thick OFC tube, increasing the thickness of Glidcop from $3 \mathrm{~mm}$ to $6 \mathrm{~mm}$ decreases the maximum temperature at the bonding surface from $140^{\circ} \mathrm{C}$ to $115^{\circ} \mathrm{C}$, and decreases the maximum effective at the bonding surface from $120 \mathrm{MPa}$ to $58 \mathrm{MPa}$. The results from the ANSYS calculation are more accurate at the bonding surface due to the assumption of "singular material" for the closed form solution.

Table 1. FM1, $h=3 \frac{W}{\mathrm{~cm}^{2}{ }^{\circ} \mathrm{C}}, 5 \mathrm{Kw}$

\begin{tabular}{|l|c|c|c|c|c|c|}
\hline & \multicolumn{3}{|c|}{$\begin{array}{c}\text { Closed Form } \\
\text { (Curve-Fit Gaussian Profile) }\end{array}$} & \multicolumn{3}{c|}{$\begin{array}{c}\text { ANSYS } \\
\text { (Real Beam Profile) }\end{array}$} \\
\hline Thickness of Glidcop $m m$ & $t=3.175$ & $t=4.5$ & $t=6.35$ & $t=3.175$ & $t=4.5$ & $t=6.35$ \\
\hline $\begin{array}{l}\text { Max. Temperature } \\
\text { on the surface }\left({ }^{\circ} \mathrm{C}\right)\end{array}$ & 213 & 214 & 216 & 199.1 & 199.2 & 200.3 \\
\hline $\begin{array}{l}\text { Max. Temperature } \\
\text { on the cooling channel }\left({ }^{\circ} \mathrm{C}\right)\end{array}$ & 110 & 100 & 93 & 100 & 87.4 & 77.5 \\
\hline $\begin{array}{l}\text { Max. Stress on } \\
\text { Glidcop surface }(\mathrm{MPa})\end{array}$ & 255 & 257 & 259 & 266 & 261 & 251 \\
\hline $\begin{array}{l}\text { Max. Temperature } \\
\text { on the bonding surface }\left({ }^{\circ} \mathrm{C}\right)\end{array}$ & 141 & 105 & 95 & 136 & 114.5 & 98 \\
\hline $\begin{array}{l}\text { Max. Stress on the } \\
\text { bonding surface }(\mathrm{MPa})\end{array}$ & 115 & 80 & 55 & 146 & 108 & 79 \\
\hline
\end{tabular}

Table 1 lists the comparative results between the closed form and ANSYS solutions. Both methods agree within $5 \%$. We curve fit the beam power (shown in Fig. 1) to a 
Gaussian-distributed heat flux for the closed form solution. The standard deviation of the curve-fit Gaussian profile is found to be $0.23 \times \sqrt{2} \mathrm{~mm}$.

The maximum temperatures and effective stresses were not calculated for vertical tubes of FM1 and PS2 because the line density at any cross section is smaller than that for the horizontal tubes [3]. This can easily be seen by the fitting curve. For horizontal tubes, the standard deviation $r_{o}$ is $.19 \mathrm{~cm}$; for vertical tubes, the standard deviation $r_{o}$ is $0.073 \mathrm{~cm}$.

\subsection{PS2}

The parameters that are used in the PS2 analysis are as follows:

\begin{tabular}{lll}
\hline & $\theta \cdot 2^{\circ}$ \\
Incident Beam Angle & $\theta$ & \\
Distance from the Source & $l$ & 21 meter \\
Peak Power & $q_{0}$ & $13 \frac{W}{\mathrm{~mm}^{2}}$
\end{tabular}

Figure 8 shows the power distribution of x-ray beam Strikes on PS2. Figures 9 and 10 show the maximum temperature on the heating surface and cooling channel wall for the different wall thickness. From Fig. 9, we note that the maximum temperature has an optimal value. For example, for $\mathrm{h}=3 \mathrm{~W} /\left(\mathrm{cm}^{2}{ }^{\circ} \mathrm{C}\right)$, the optimal thickness is $5 \mathrm{~mm}$ to obtain a minimum surface temperature of about $224^{\circ} \mathrm{C}$. Lower temperatures can only be obtained with a higher " $\mathrm{h}$ " value, above $\mathrm{h}=3 \mathrm{~W} /\left(\mathrm{cm}^{2}{ }^{\circ} \mathrm{C}\right)$. From Fig. 10, it is seen that, under these conditions, the maximum cooling channel temperature will be about $120^{\circ} \mathrm{C}$. Increasing the channel wall thickness (Glidcop plus OFC) from $5 \mathrm{~mm}$ to $10 \mathrm{~mm}$ will help reduce the cooling channel wall temperature to $100{ }^{\circ} \mathrm{C}$ while keeping the maximum temperature about the same $\left(230^{\circ} \mathrm{C}\right)$.

Figure 11 shows the maximum effective stress on the Glidcop surface. The slopes of the maximum effective stress curves match the maximum temperature curves as expected.

Figures 12 and 13 show the maximum temperature and maximum effective stress, respectively, at the bonding surface for a $3.175 \mathrm{~mm}$ thick OFC tube. It is desirable to keep the temperature and thermal stress low at the interface to attain a safety factor of 4 or better so that one does not need to consider the thermal fatigue in OFC. For example, for $\mathrm{h}=3 \mathrm{~W} /\left(\mathrm{cm}^{2}{ }^{\circ} \mathrm{C}\right)$ with a $3 \mathrm{~mm}$ thick OFC tube, increasing the thickness of Glidcop from $3 \mathrm{~mm}$ to $6 \mathrm{~mm}$ decreases the maximum temperature at the bonding surface from $155^{\circ} \mathrm{C}$ to $125^{\circ} \mathrm{C}$, and decreases the maximum effective stress at the bonding surface from $130 \mathrm{MPa}$ to $65 \mathrm{MPa}$. The results from the ANSYS calculations are more accurate at the bonding surface because of the assumption " singular material" for the closed form solution.

Table 2 lists the comparative results between the closed form and ANSYS solutions. Both methods agree within $5 \%$. We curve fit the beam power (shown in Fig. 1) to a 
Gaussian-distributed heat flux for the closed form solution. The standard deviation of the curve-fit Gaussian profile is found to be $0.24 \times \sqrt{2} \mathrm{~mm}$.

Table 2. PS2, $h=3 \frac{W}{\mathrm{~cm}^{2}{ }^{\circ} \mathrm{C}}, 5 \mathrm{Kw}$

\begin{tabular}{|c|c|c|c|c|c|c|}
\hline & \multicolumn{3}{|c|}{$\begin{array}{c}\text { Closed Form } \\
\text { (Curve-Fit Gaussian Profile) }\end{array}$} & \multicolumn{3}{|c|}{$\begin{array}{c}\text { ANSYS } \\
\text { (Real Beam Profile) }\end{array}$} \\
\hline Thickness of Glidcop $\mathrm{mm}$ & $t=3.175$ & $t=4.5$ & $t=6.35$ & $t=3.175$ & $t=4.5$ & $t=6.35$ \\
\hline $\begin{array}{l}\text { Max. Temperature } \\
\text { on the surface }\left({ }^{\circ} \mathrm{C}\right)\end{array}$ & 225 & 226 & 228 & 201.1 & 201.4 & 199.7 \\
\hline $\begin{array}{l}\text { Max. Temperature } \\
\text { on the cooling channel }\left({ }^{\circ} \mathrm{C}\right)\end{array}$ & 122 & 110 & 100. & 103.2 & 91 & 80.8 \\
\hline $\begin{array}{l}\text { Max. Stress on } \\
\text { Glidcop surface }(M P a)\end{array}$ & 260 & 265 & 270 & 260 & 256 & 250 \\
\hline $\begin{array}{l}\text { Max. Temperature } \\
\text { on the bonding surface }\left({ }^{\circ} \mathrm{C}\right)\end{array}$ & 150 & 138 & 120 & 141.5 & 120 & 102.4 \\
\hline $\begin{array}{l}\text { Max. Stress on the } \\
\text { bonding surface }(M P a)\end{array}$ & 125 & 90 & 65 & 150 & 113 & 83 \\
\hline
\end{tabular}

Fig. 14 shows the temperature distribution from ANSYS calculations. The finite element model of PS2 has approximately four thousand nodes and three thousand elements.

\section{Conclusion \& Future Work}

The optimized values of maximum stress show some discrepancies due to :

1. the difference between the real beam profile (ANSYS) and a curve-fit Gaussian profile (closed form),

2. an assumption for the closed form solution is that the magnitude of the cross section (xy plane) of these devices is much smaller than that of the length ( $z$ axis). However, by increasing the Glidcop thickness, the cross section ( $x y$ plane) becomes bigger, and this assumption becomes less valid.

Nevertheless, the trend from ANSYS is such that the thicker the layer of Glidcop, the lower the maximum effective stress will be when the real beam profile is used. The total material thickness is kept between $6.25 \mathrm{~mm}$ to $9.5 \mathrm{~mm}$ for the ANSYS calculations.

FM1 and PS2 of the front end are each made of two different materials, Glidcop and OFC. Glidcop has much better strength above $150^{\circ} \mathrm{C}$. The purpose of using a Glidcop plate is to allow the beam to strike the Glidcop surface; the OFC acts as a cooling sub-structure. Copper sponge is brazed to the inside of the OFC tube, and a Glidcop face plate is bonded to the outside surface of the OFC. During the brazing/bonding process, the tensile strength of OFC drops. Figure 15 shows the softening curves for OFC [10]. 
It is, therefore, worthwhile to optimize the Glidcop thickness to reduce the maximum effective stress at the bonding surface without needing to consider the thermal fatigue in OFC.

From Tables 1 and 2, it is found that the maximum effective stress at the Glidcop surface is about $260 \mathrm{MPa}$ regardless of the total thickness on these two devices. The yield strength of Glidcop AL-15 at $220^{\circ} \mathrm{C}$ is about $350 \mathrm{MPa}$ [6].

Stephens and Schmale [7] demonstrate that Glidcop AL-15 can be sub jected to high temperature $\left(870^{\circ} \mathrm{C}\right)$ braze thermal cycles without damage. Figure 16 shows the tensile properties of Glidcop AL-15 under braze thermal cycles [7]. According to Fig. 16, the Glidcop face plate will retain its almost original mechanical strength under bonding/brazing.

In order to obtain thermal fatigue properties of Glidcop at $220^{\circ} \mathrm{C}$, testing should be done in the near future [11]. Daniels and Dorn [12] mentioned that the thermal failure cycle is directly related to temperature, frequency, activation energy, and stress level. A new relationship of thermal fatigue is proposed by Udouchi and Wada [13] utilizing the Manson-Coffin relation :

$$
N^{k} \Delta \epsilon^{v p}\left[-\frac{Q_{1}}{T_{a v}}+\left[1+C_{2} \Delta T \exp \left(-\frac{Q_{1}}{\Delta T}\right)\right]\right]=C_{1},
$$

where

$$
\begin{aligned}
& \Delta T=\text { amplitude of the temperature cycle, } \\
& T_{a v}=\text { average temperature in the cycle, } \\
& \Delta \epsilon^{v p}=\text { plastic strain range in the cycle, }
\end{aligned}
$$

and material constants $k, C_{1}, C_{2}$, and $Q_{1}$ are to be determined from the experiment.

To braze a beryllium plate on the OFC sub-structure will help the synchrotron radiation to penetrate the beryllium material. In the preliminary analysis of this design, the maximum temperature is about $100^{\circ} \mathrm{C}$. CESR has successfully used beryllium material brazed on copper tubing on the absorber [14].

The mechanical strength of the bonding and the OFC tube is not an issue if the Glidcop thickness can be optimized as described above.

\section{Acknowledgments}

This work was supported by the U.S. Department of Energy, BES-Materials Science, under contract W-31-109-Eng-38.

\section{References}

[1] D. Shu, J. Barraza, T. Sanchez, R. W. Nielsen, J. T. Collins, and T. M. Kuzay. Front End Designs for the 7-GeV Advanced Photon Source. these Proceedings (7th Nat. Conf. on SRI, Baton Rouge, LA, USA, 1991), Nucl. Instr. and Meth. A319 (1992) 63. 
[2] Tuncer M. Kuzay, J. T. Collins, A. M. Khounsary, and M. Gilberto. Enhanced Heat Transfer With Wool-Filled Tubes. ASME/JSME 3rd Joint Heat Engineering Conference, Reno, Nevada, March, 1991.

[3] H.L. Nian, I.C. Albert Sheng and Tuncer M. Kuzay. Thermal Analysis of a Photon Shutter for APS Front Ends, these Proceedings (7th Nat. Conf. on SRI, Baton Rouge, LA, USA, 1991), Nucl. Instr. and Meth. A319 (1992) 197.

[4] Deming Shu, H.L. Nian, Zhibi Wang, J. T. Collins, David G. Ryding, and Tuncer M. Kuzay. The First Photon Shutter Development for APS Insertion Device Beam Line Front Ends. SPIE'92, Technical Conference 1739, High Heat Flux Engineering, July 19-24, 1992, San Diego, CA.

[5] G. K. Shenoy, P. J. Viccaro, and D. M. Mills. Characteristics of the 7-GeV Advanced Photon Source: a Guide for Users. ANL - 88/9, 1988.

[6] SCM Metal Products, Inc. Glidcop Grade AL-15 Dispersion Strengthened Copper.

[7] J. J. Stephens, and D. T. Schmale. The Effect of High Temperature Braze Thermal Cycles on Mechanical Properties of a Dispersion Strengthened Copper Alloy. SAND871296 - UC-20.

[8] M. Abramowitz and I. A. Stegum, Handbook of Mathematical Functions, Dover Publications, Inc., 1965, p.228.

[9] J. H. Weiner and B. A. Boley. Theory of Thermal Stresses. New York, Wiley, 1923

[10] Hitachi Cable America Inc. Hitachi Oxygen Free Copper, Application Technology.

[11] I. C. Sheng and J. Howell. Thermal Analysis of the Crotch Absorber in APS. SPIE'92, Technical Conference 1739, High Heat Flux Engineering, July 19-24, 1992, San Diego, CA.

[12] Howard L. Leve, et al. Metal Fatigue : Theory and Design. John Wiley \& Sons, Inc., 1969.

[13] T. Udouchi and T. Wada. Thermal Effect on Low-cycle Fatigue Strength of Steels. Proc. International Conference on Thermal Stress and Thermal Fatigue. pp. 104, 1964.

[14] D. M. Mills, D. H. Bilderback, and B. W. Batterman. Thermal Design of Synchrotron Radiation Ports at CESR. IEEE Transactions on Nuclear Science, NS-26:3854-3856, 1979. 


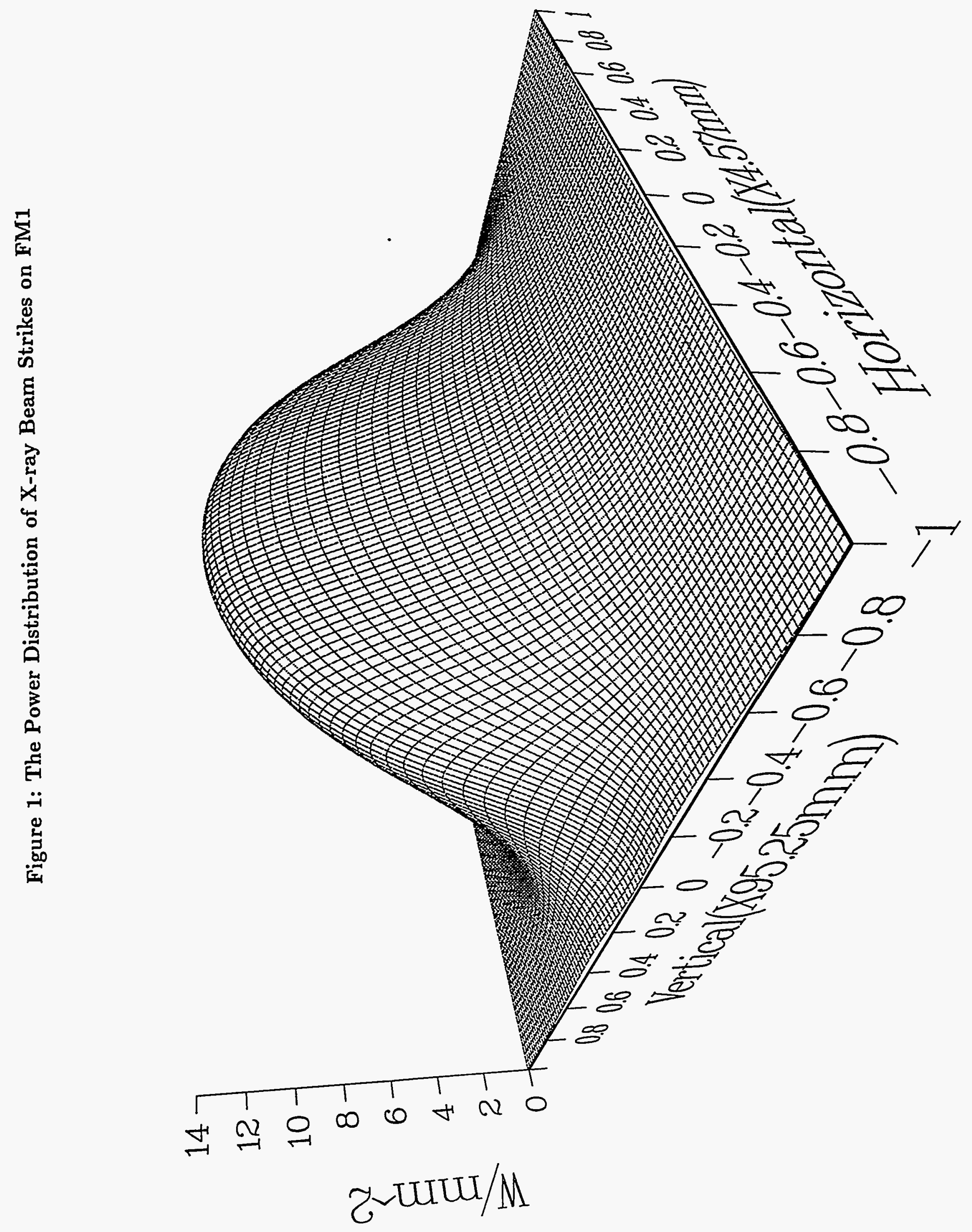




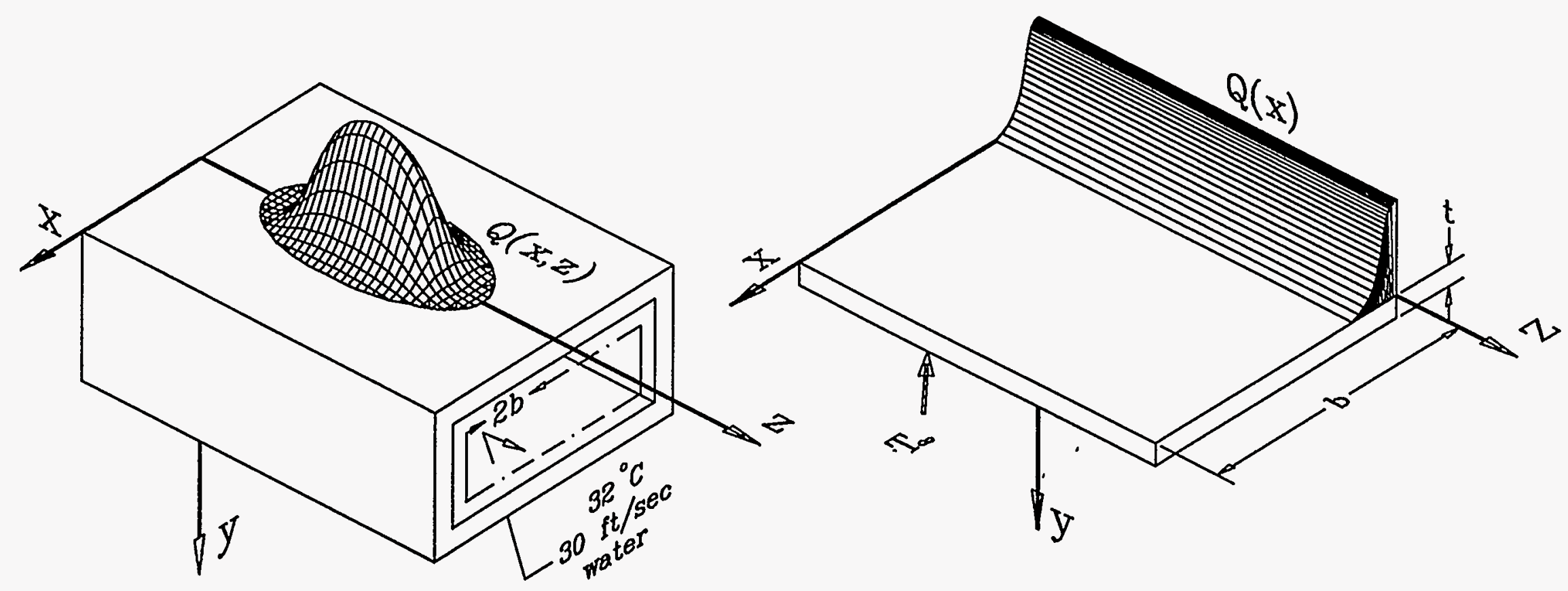

Channel Model with Real Beam

Profile (ANSYS)

Simplified Model with Curve-Fit

Gaussian Profile (Closed Form)

Fig. 2 Channel Model \& Simplified Model 
Figure 3: Maximum Surface Temperature for Glidcop (FM1)

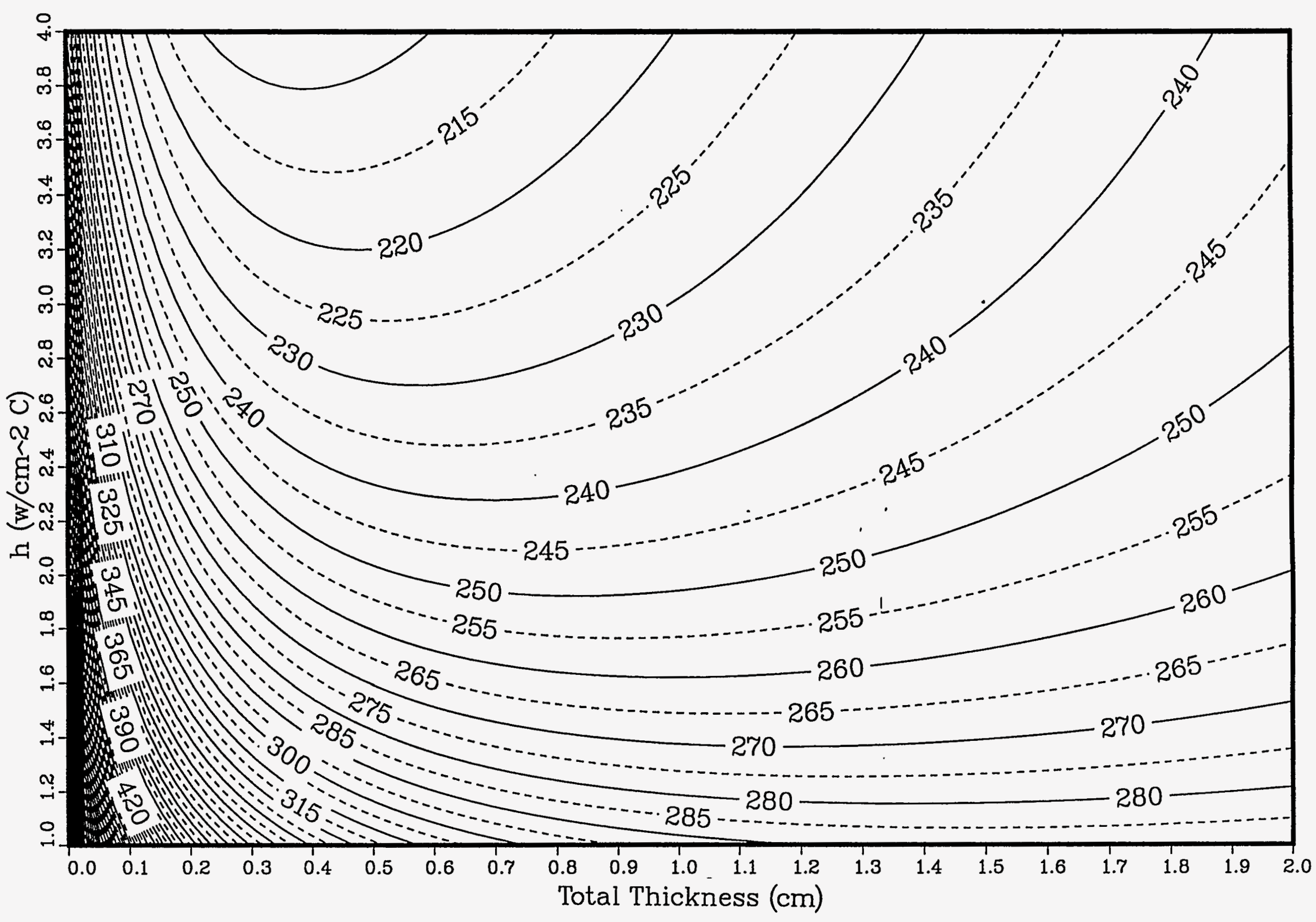


Figure 4: Maximum Cooling Channel Wall Temperature (FM1)

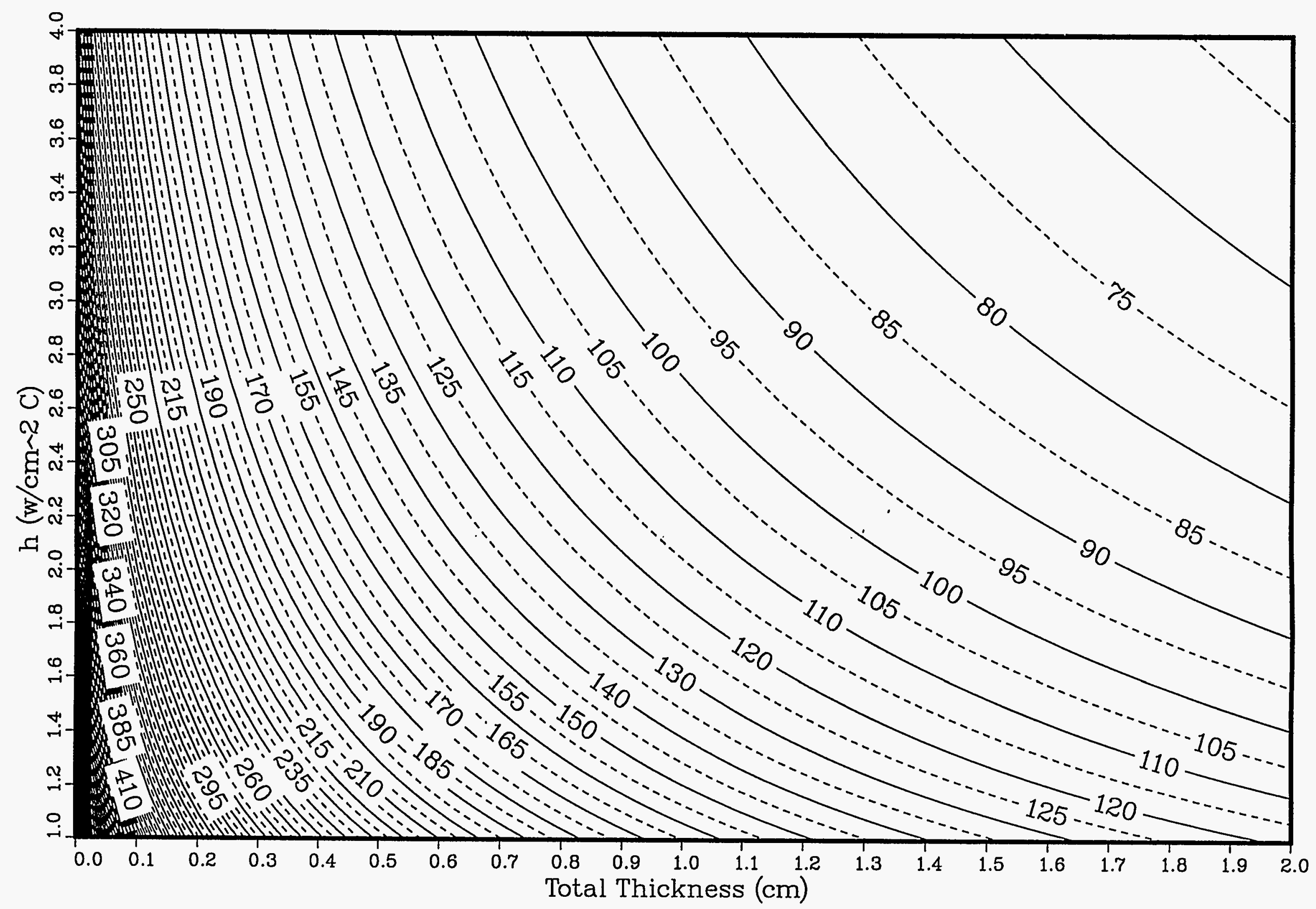









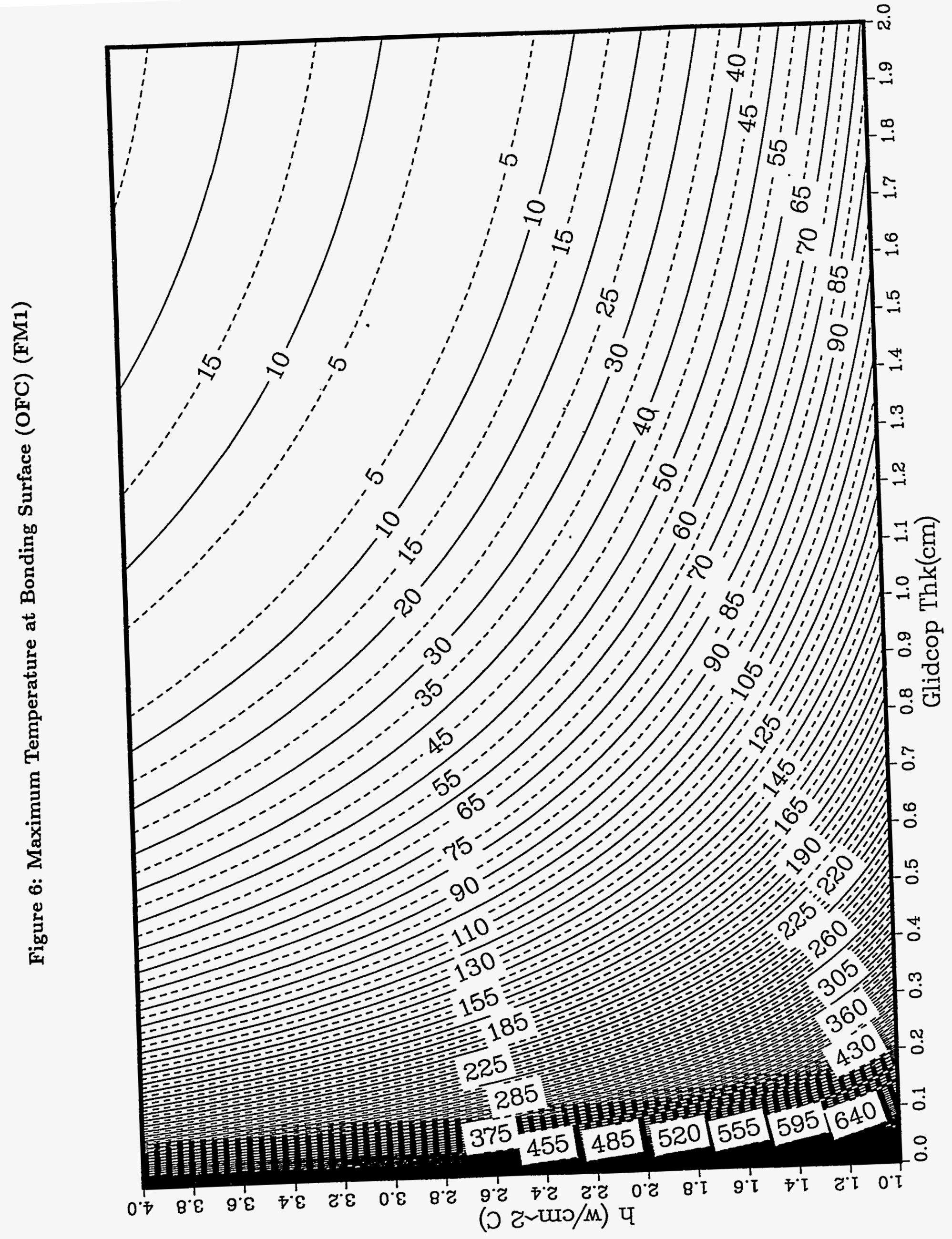




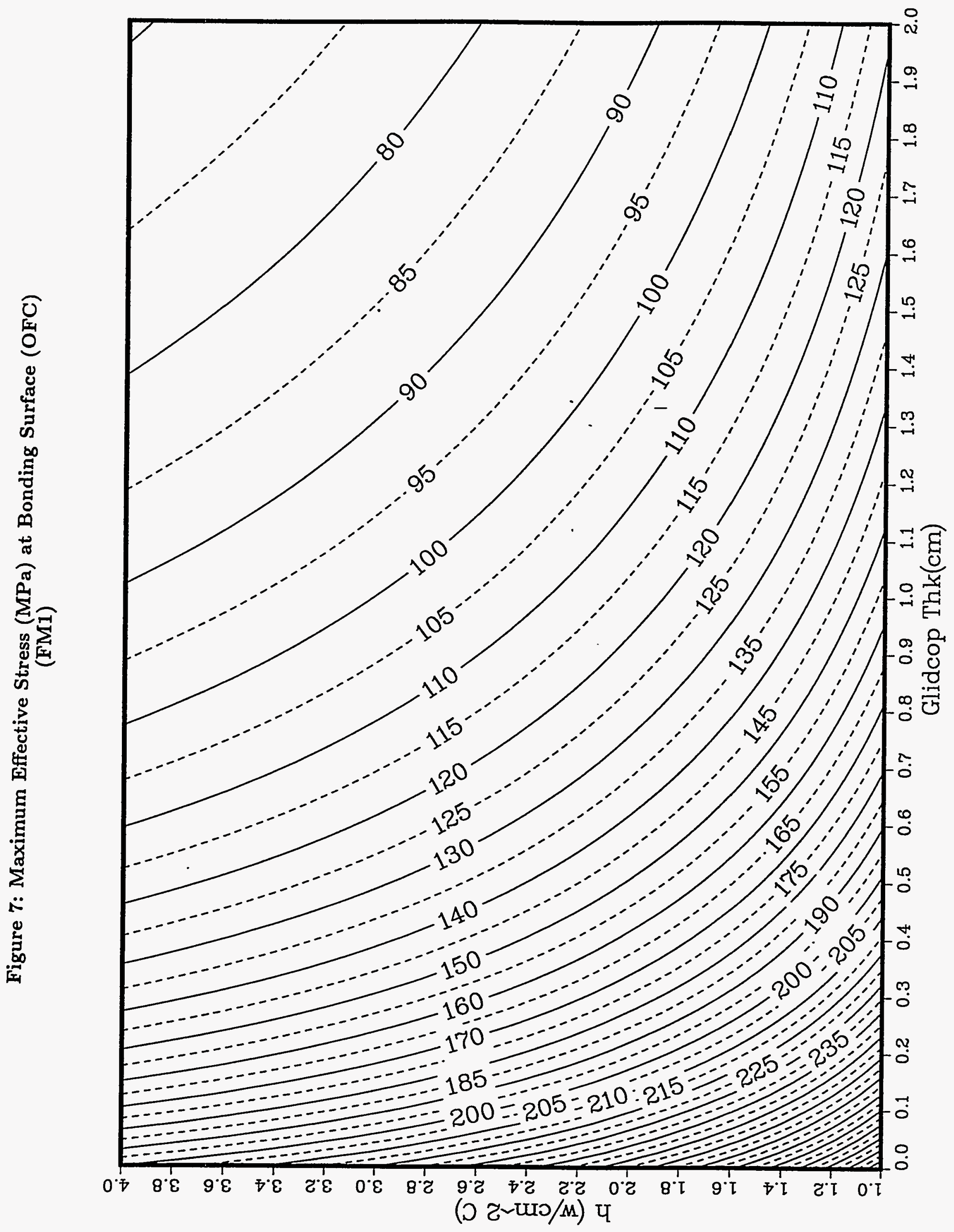




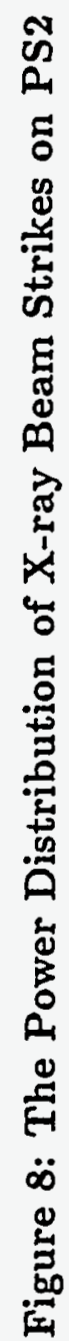

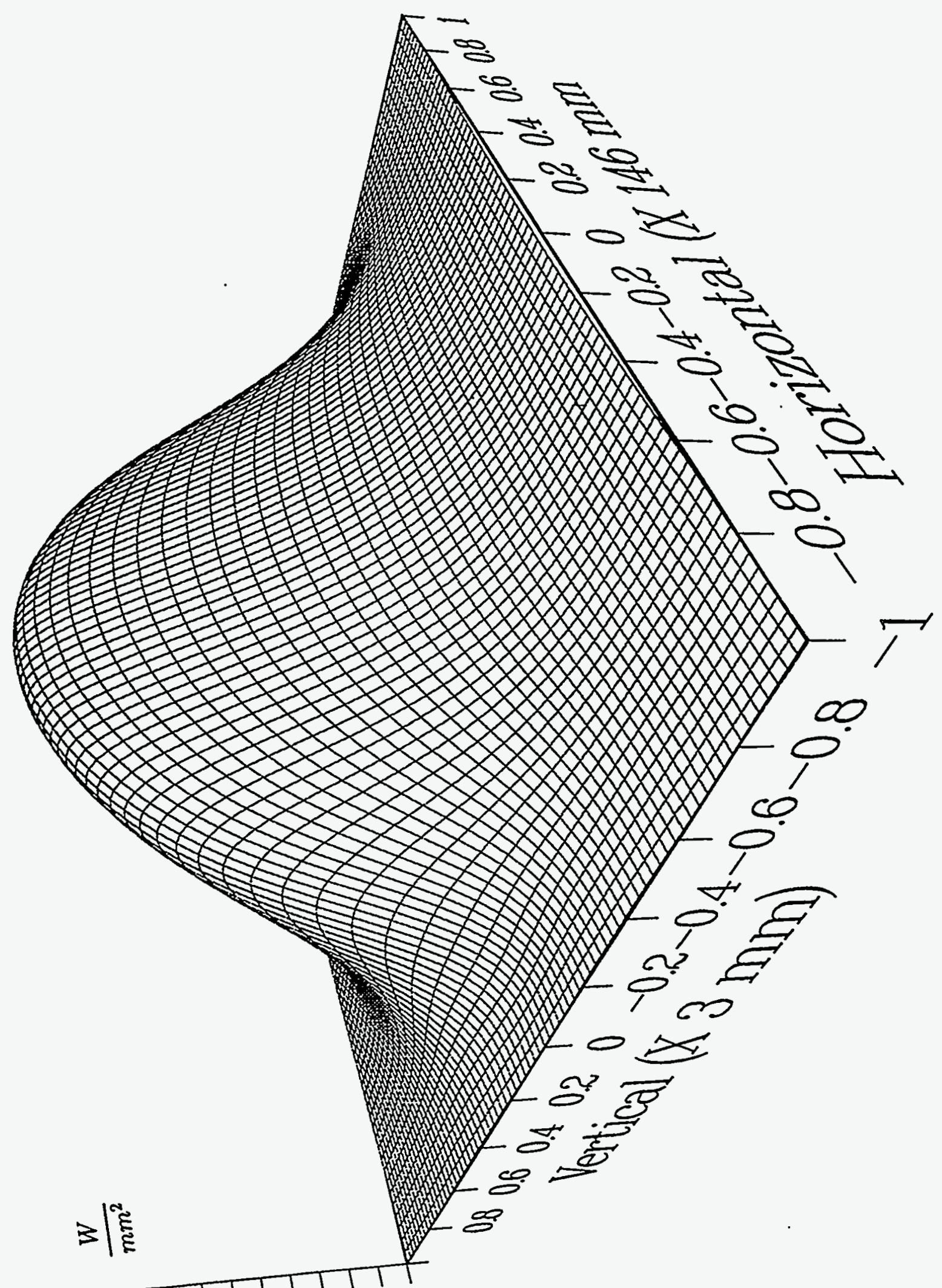

cind 


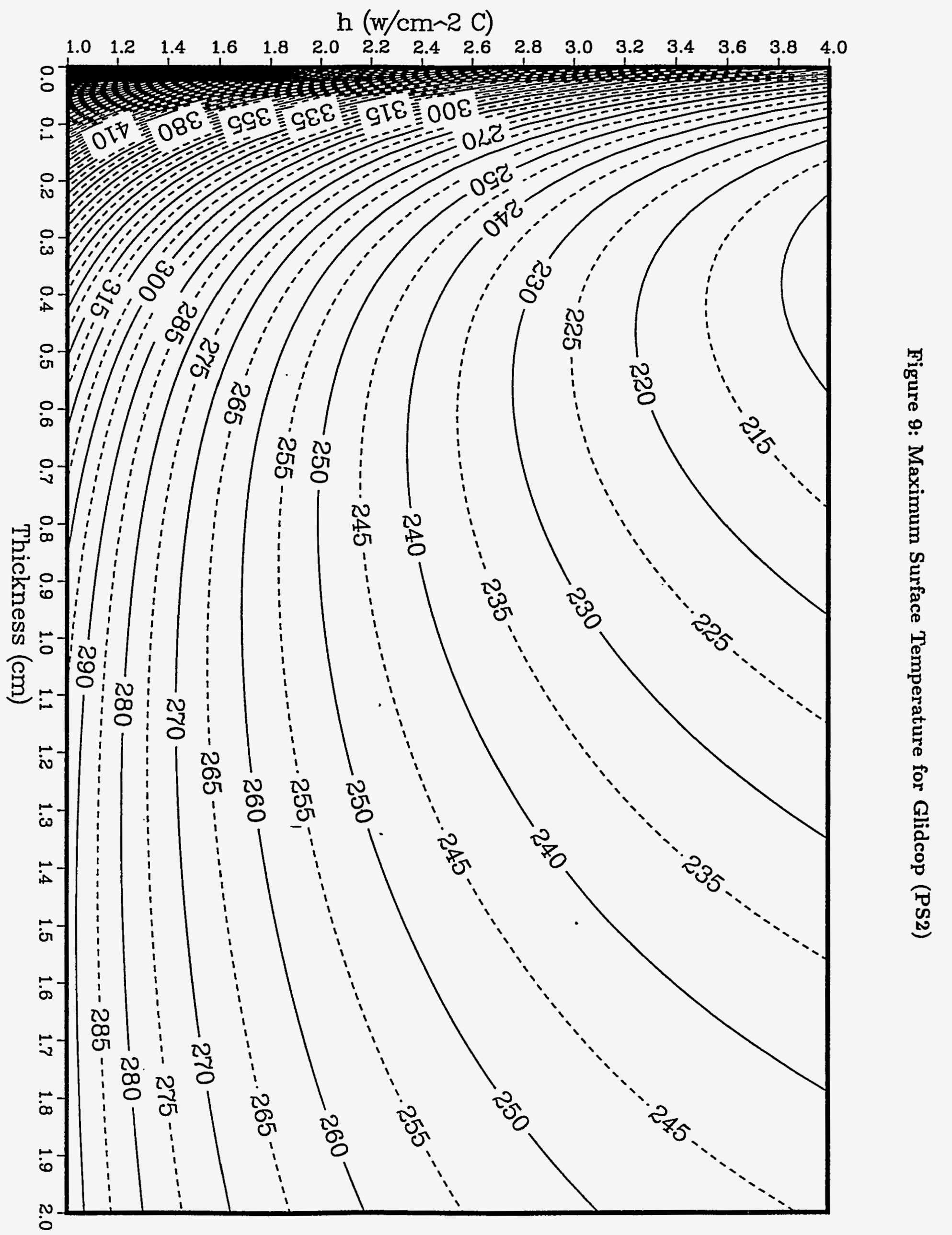


Figure 10: Maximum Cooling Channel Wall Temperature (PS2)

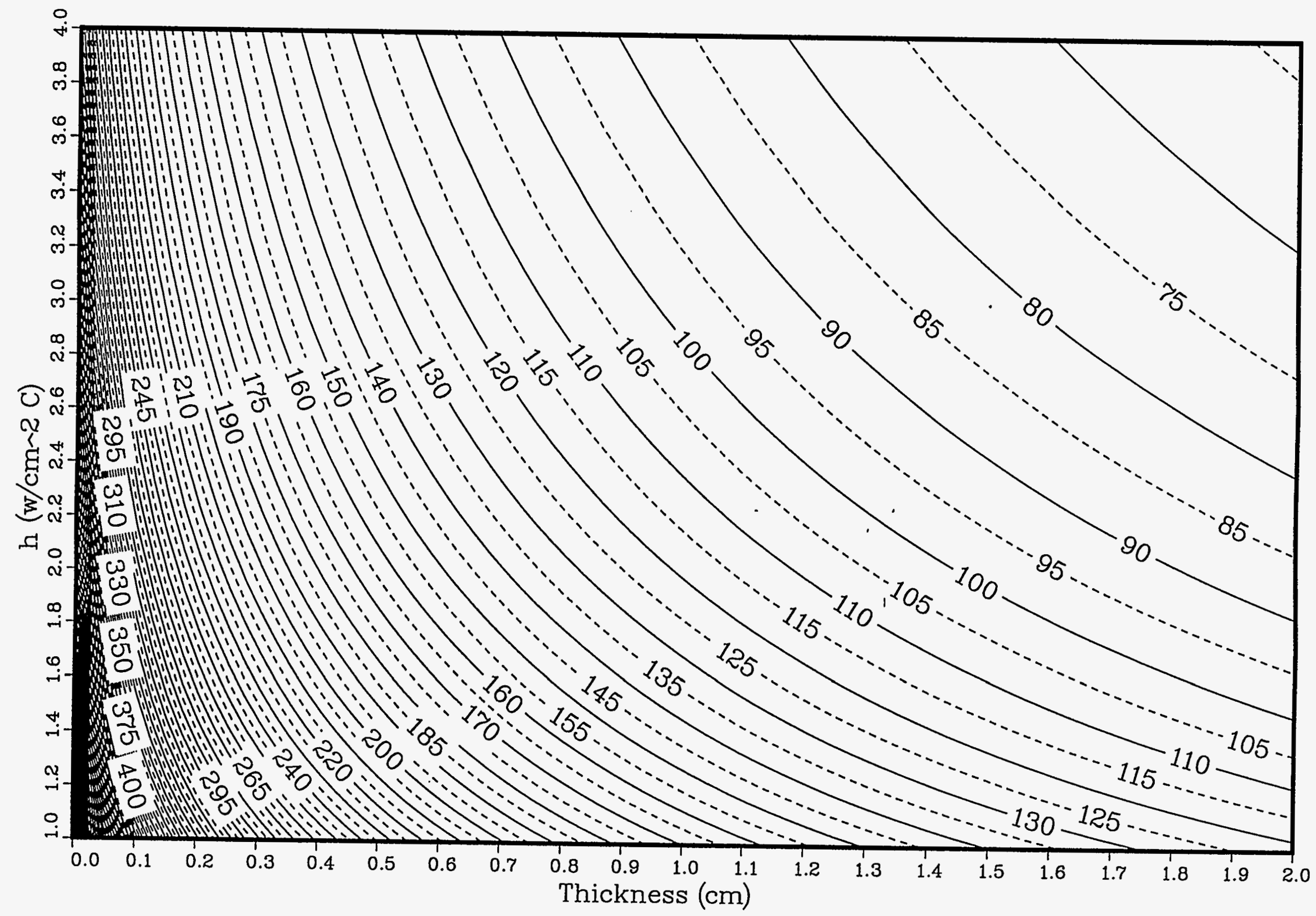


Figure 11: Maximum Effective Stress (MPa) for Glidcop (PS2)

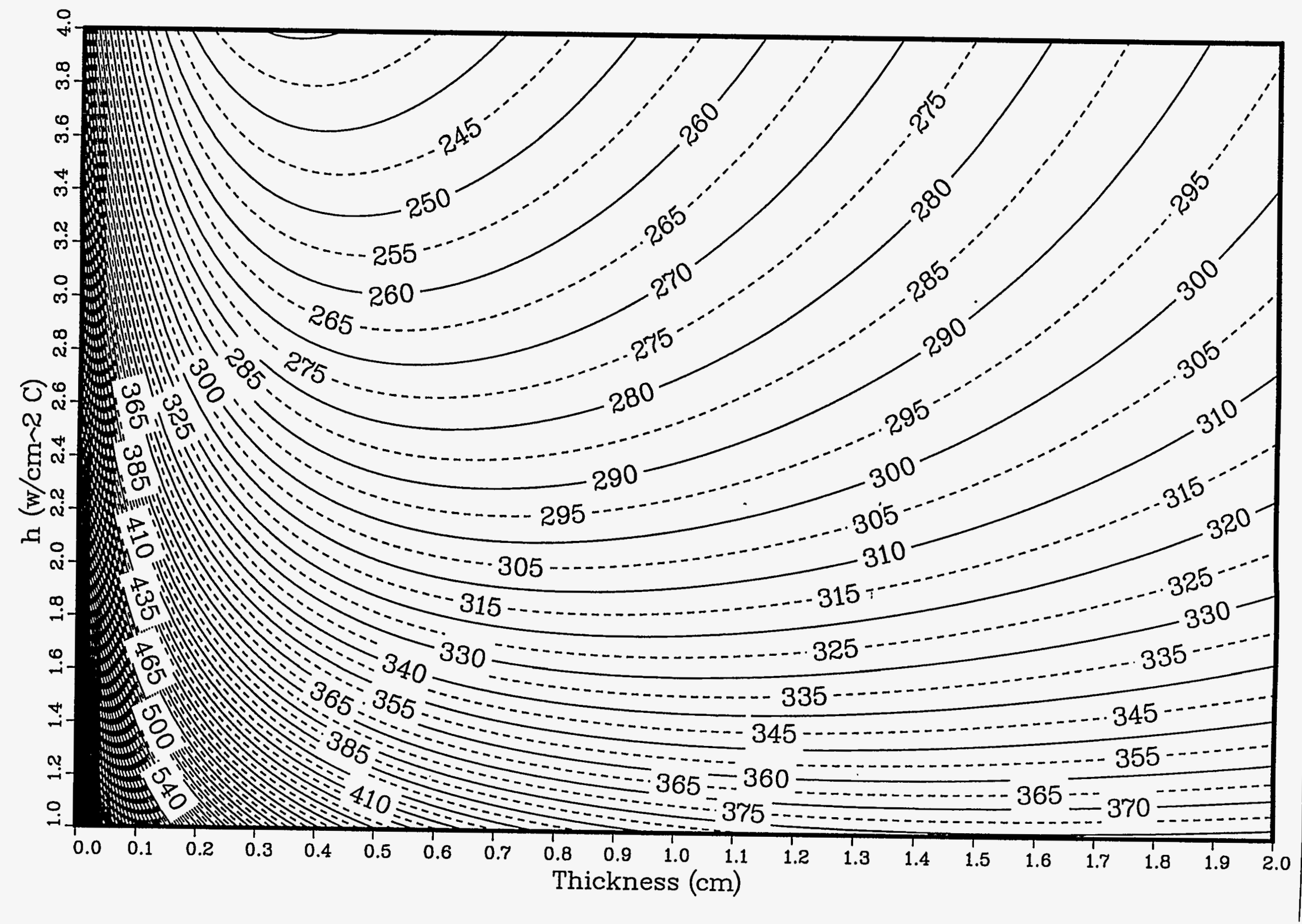


$\mathrm{h}(\mathrm{w} / \mathrm{cm} \sim 2 \mathrm{C})$

$\begin{array}{llllllllllllllll}1.0 & 1.2 & 1.4 & 1.6 & 1.8 & 2.0 & 2.2 & 2.4 & 2.6 & 2.8 & 3.0 & 3.2 & 3.4 & 3.6 & 3.8 & 4.0\end{array}$

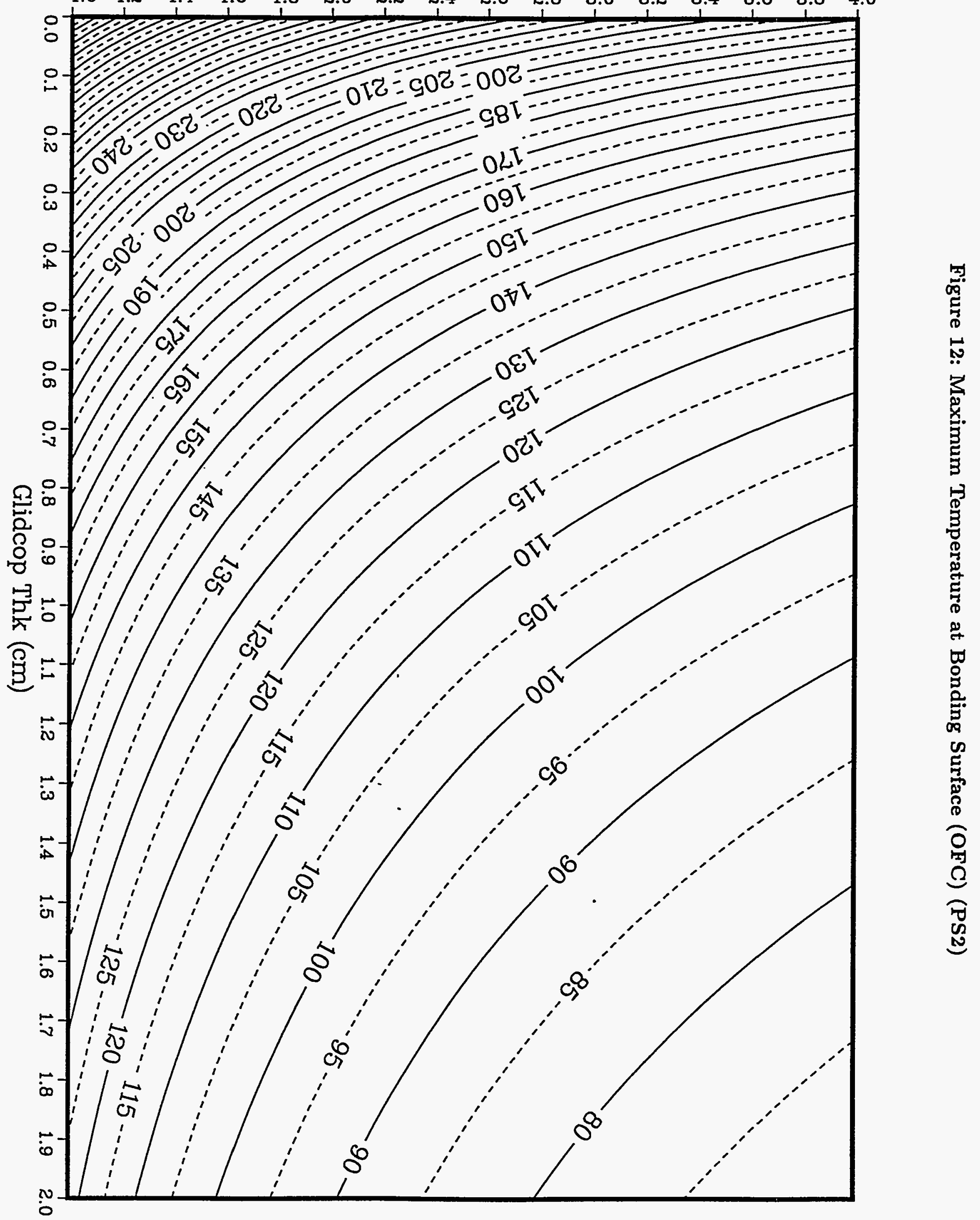




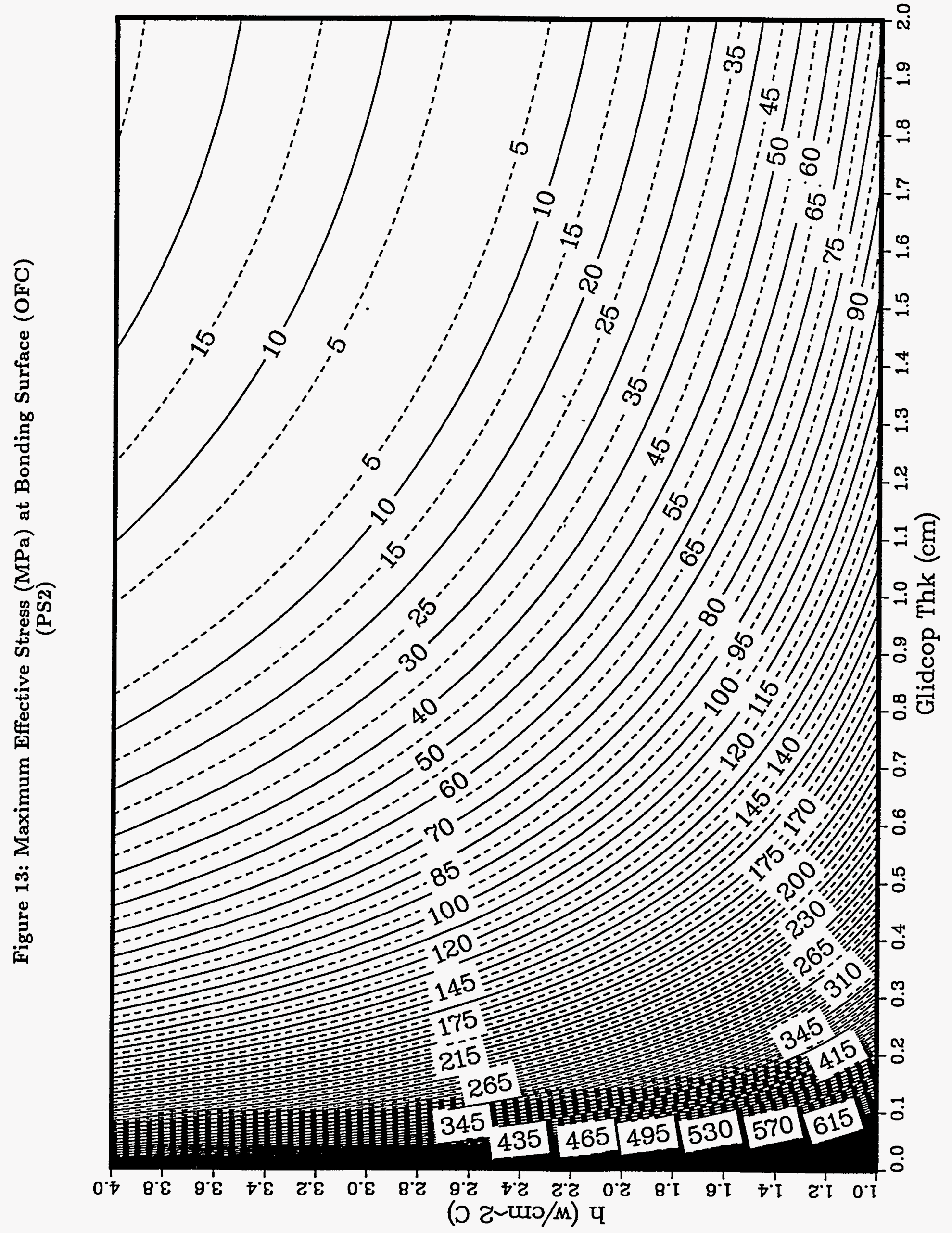


is

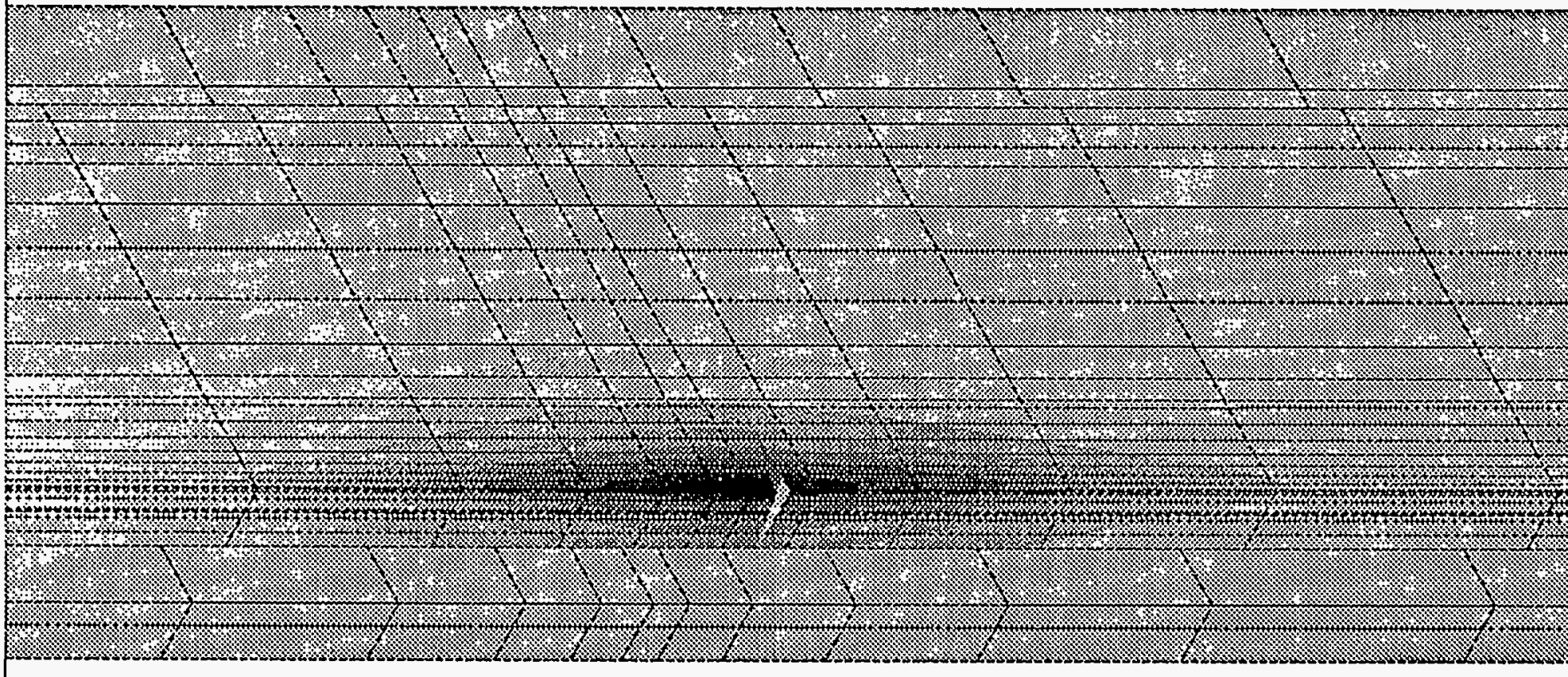

Photon Shutter 2 $\mathrm{h}=3 \mathrm{~W} / \mathrm{cm}^{\wedge} 2 \mathrm{C}$

$\operatorname{Max} \mathrm{q}=13 \mathrm{~W} / \mathrm{mm}^{\wedge} 2$

Dist $=21 \mathrm{~m}$

Ang $=2$ Deg.

.125" Glidcop

$.125^{\prime \prime}$ OFC

$\operatorname{Min} \mathrm{T}=32 \mathrm{C}$

$\operatorname{Max} \mathrm{T}=201 \mathrm{C}$

$32 \mathrm{C}$
$51 \mathrm{C}$
$70 \mathrm{C}$
$88 \mathrm{C}$
$107 \mathrm{C}$
$126 \mathrm{C}$
$144 \mathrm{C}$
$163 \mathrm{C}$
$182 \mathrm{C}$
$200 \mathrm{C}$

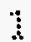

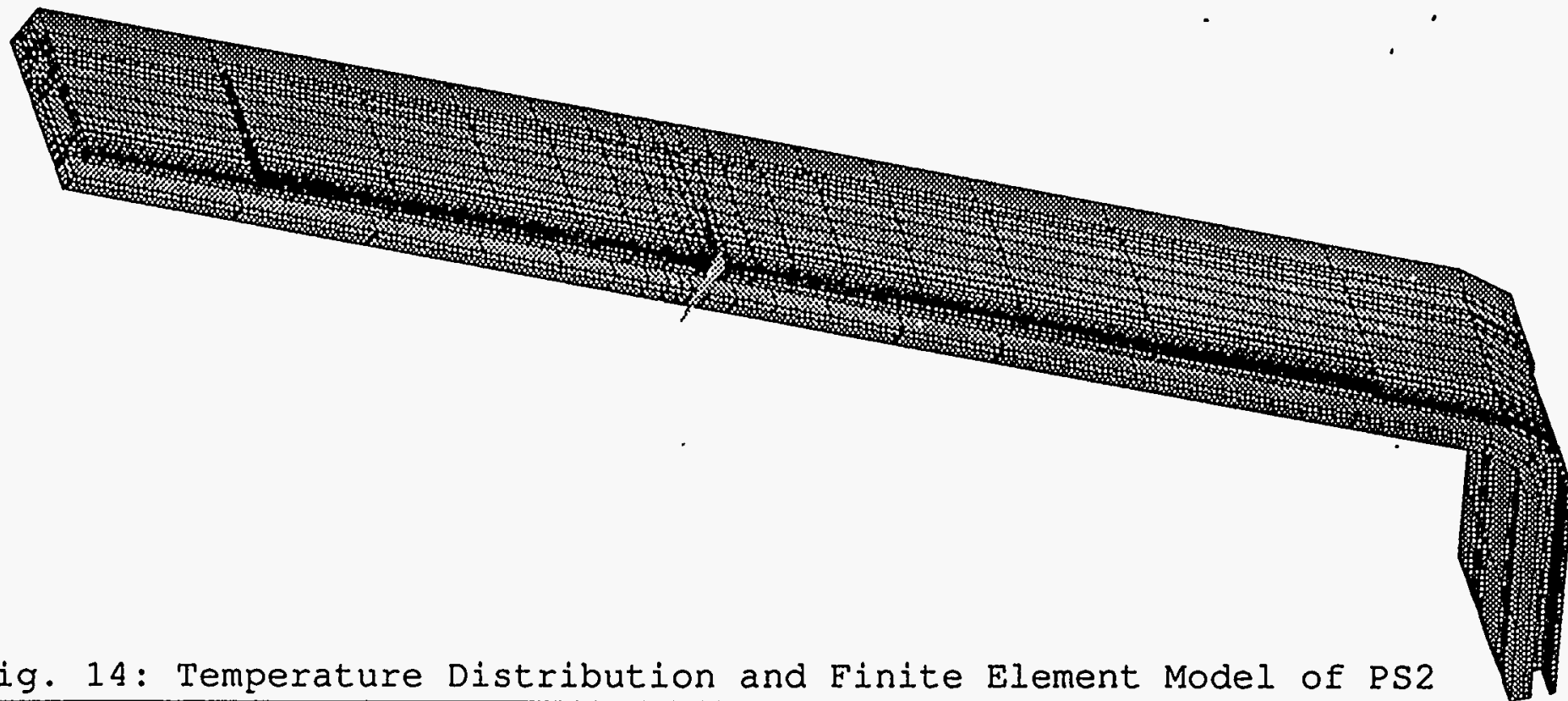




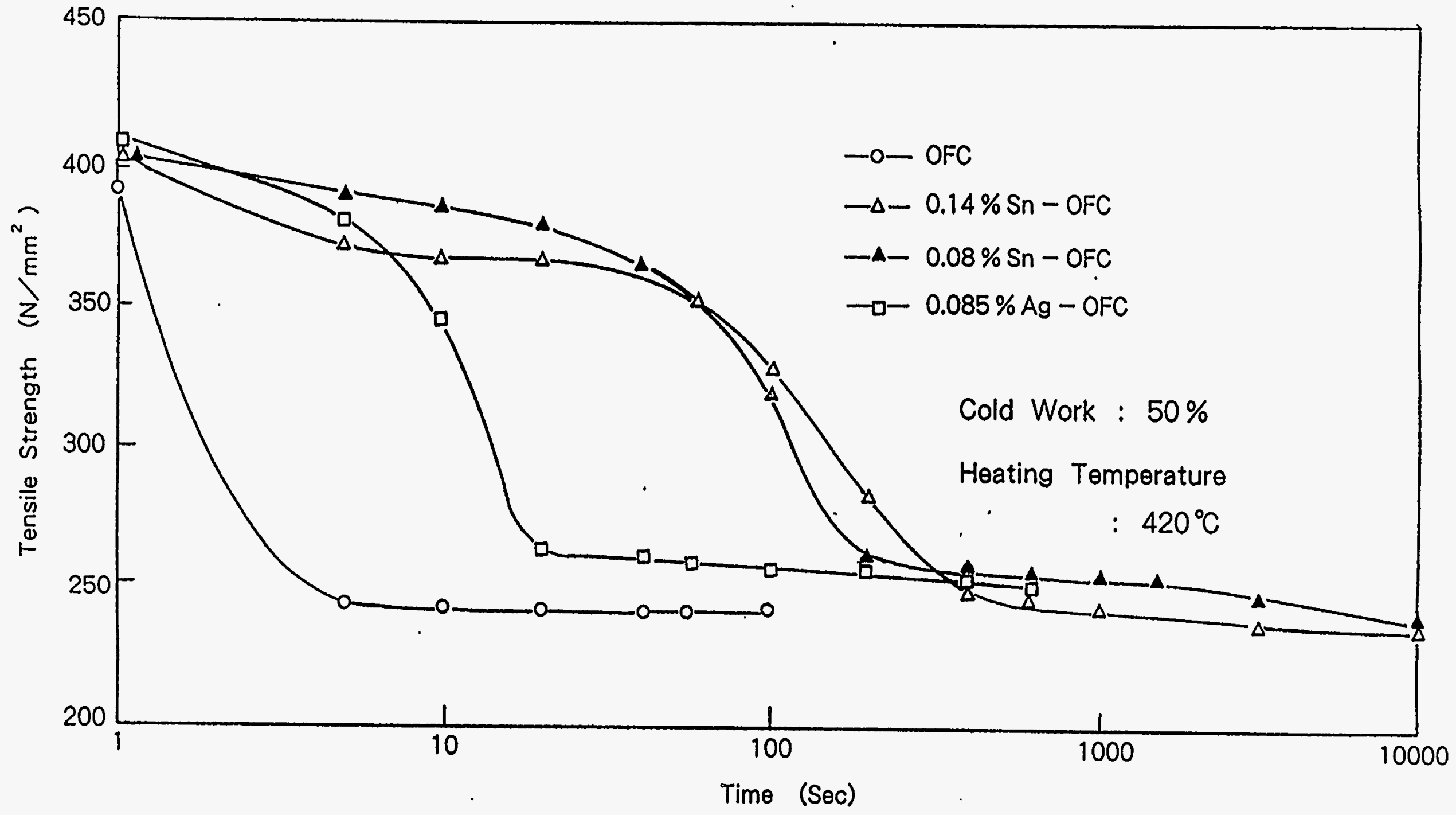

Figure 15: Isothermal Softening Curves for OFC, SN-OFC and Ag-OFC 
Figure 16: Room Temperature Tensile Properties of AL-15 Tube Specimens Subjected to A Standard (5 Minute at $870{ }^{\circ} \mathrm{C}$ ) Ticusil Braze Cycle Compared to Cold-Worked AL-15.

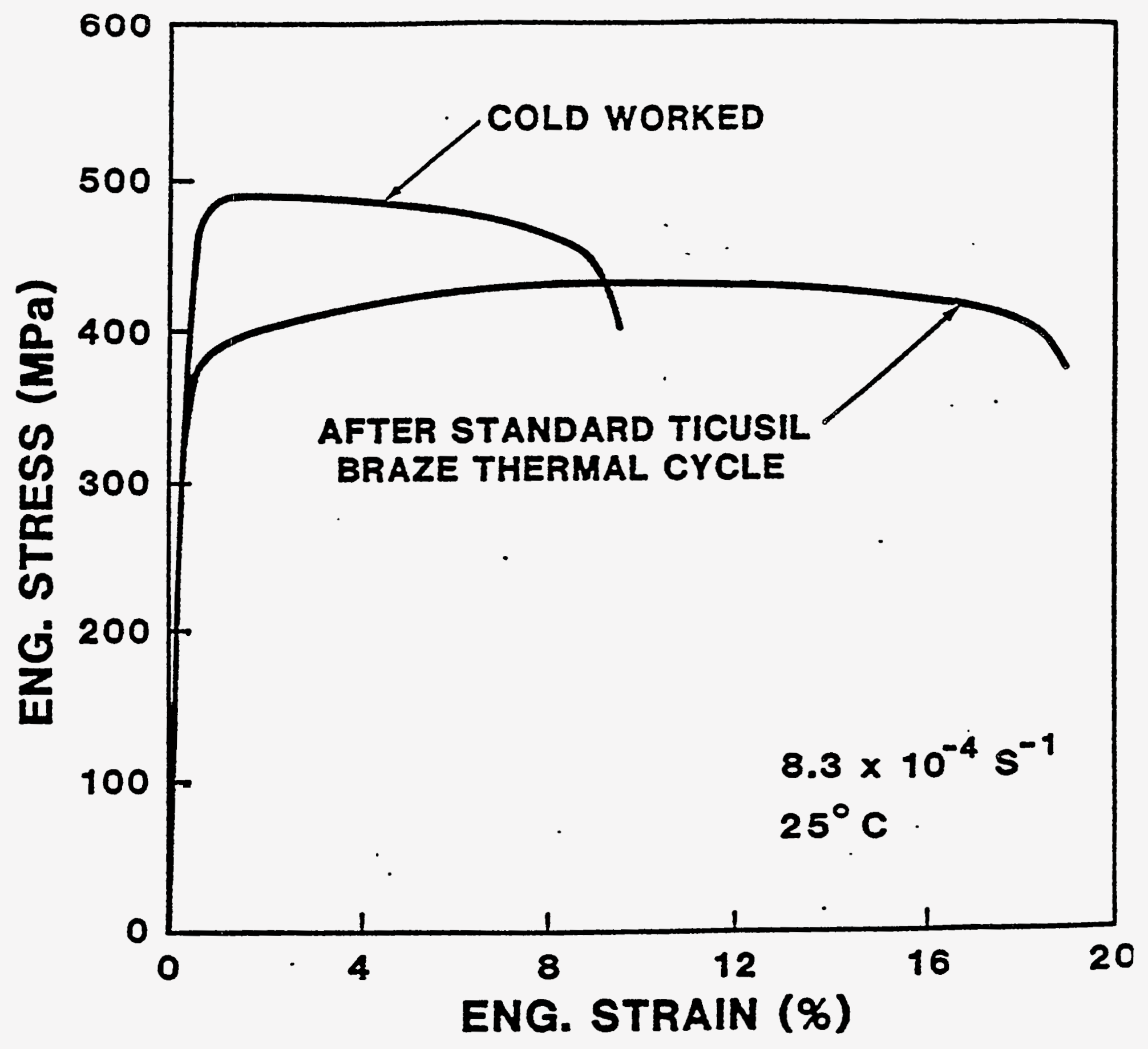

